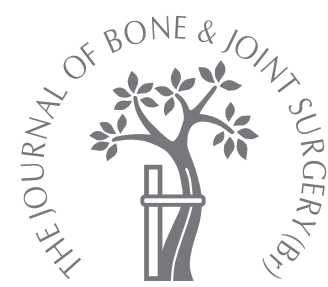

\title{
Femoral impaction bone grafting with the Exeter stem - the Swedish experience
}

\author{
SURVIVORSHIP ANALYSIS OF 1305 REVISIONS PERFORMED \\ BETWEEN 1989 AND 2002
}

\begin{abstract}
E. Ornstein, L. Linder, J. Ranstam, S. Lewold, T. Eisler, M. Torper
\end{abstract}

From Hässleholm Hospital, Hässleholm, Sweden
E. Ornstein, MD, PhD, Consultant Orthopaedic Surgeon

- L. Linder, MD, PhD, Consultant Orthopaedic Surgeon, Professor - $\mathrm{S}$. Lewold, $\mathrm{MD}, \mathrm{PhD}$ Consultant Orthopaedic Surgeon

M. Torper, MD, Senior Registrar

Department of Orthopaedic Surgery

Hässleholm Hospital, SE-28125 Hässleholm, Sweden.

J. Ranstam, PhD, CStat, Director

Swedish National Competence Musculoskeletal Centre (NKO) University of Lund, SE-22185 Lund, Sweden.

T. Eisler, $\mathrm{MD}, \mathrm{PhD}$, Consultant Orthopaedic Surgeon

The Swedish Hip Arthroplasty Registry

Sahlgrenska University Hospital, SE-43130 Mölndal, Sweden.

Correspondence should be sent to Dr E. Ornstein; e-mail: ewald.ornstein@skane.se

(C)2009 British Editorial Society of Bone and Joint Surgery doi:10.1302/0301-620X.91B4. $21319 \$ 2.00$

J Bone Joint Surg [Br] 2009;91-B:441-6. Received 22nd May 2008; Accepted after revision 17 December 2008

We identified 1305 femoral impaction bone grafting revisions using the Exeter stem performed between 1989 and 2002 in 30 hospitals throughout Sweden. There were 1188 patients with a mean age of 71 years (29 to 94) followed up for between five and 18 years.

The participating departments reported 70 further revisions in total, of which 57 could also be identified on the Swedish National Arthroplasty Registry.

Kaplan-Meier survivorship for all causes of failure was $94.0 \%$ (95\% confidence interval (CI) 92 to 96$)$ for women and $94.7 \%(95 \% \mathrm{Cl}, 92$ to 96$)$ for men at 15 years. Survivorship at 15 years for aseptic loosening was $99.1 \%$ (95\% Cl 98.4 to 99.5), for infection $98.6 \%(95 \% \mathrm{Cl} 97.6$ to 99.2), for subsidence $99.0 \%$ (95\% Cl 98.2 to 99.4 ) and for fracture $98.7 \%$ (95\% Cl 97.9 to 99.2$)$

Statistically significant predictors of failure were the year in which revision was conducted ( $p<0.001$ ). The number of previous revisions was slightly above the level of signifance $(p=0.056)$. Age, gender, the length of the stem and previous septic loosening were not predictors of failure $(p=0.213, p=0.399, p=0.337, p=0.687$, respectively). The difference in survivorship between high- and low-volume departments was only $3 \%$ at ten years.

We conclude that impaction bone grafting with the Exeter stem has an excellent longterm survivorship following revision arthroplasty. The technique of impaction grafting appears to be reliable, can be learned rapidly and produces a predictably low incidence of aseptic loosening.

Cemented revision combined with impaction bone grafting has become an accepted method of dealing with the bone loss encountered in loosening of the femoral stem. The method was developed for the polished Exeter stem (Stryker Orthopaedics, Mahwah, New Jersey) ${ }^{1}$ but subsequently the technique has been successfully applied to other stems. ${ }^{2,3}$

Most authors agree that the method is technically demanding, sometimes time-consuming and has a significant learning curve., ${ }^{2,4}$ Although a number of both intra- and postoperative complications have been described, many have been shown to be of little or no consequence to the long-term result. ${ }^{4}$ The benefits of predictable relief from pain ${ }^{1,5}$ and the prospect of bone regeneration ${ }^{1}$ support the continued use of the method.

Long-term follow-up reports have emerged from the developing centres in Exeter, United Kingdom and Nijmegen, The Netherlands. ${ }^{6,7}$ The most common complications have been infection and periprosthetic fracture, whereas aseptic loosening has been notably uncommon ${ }^{6}$ or even absent. ${ }^{7}$ Good medium-term results have been reported from other centres, in Europe, ${ }^{8}$ North America ${ }^{9-11}$ and the Far East. ${ }^{12}$ However, there has been no report of the longterm results of this technique when performed in a large number of orthopaedic departments.

In 1992, the first dedicated impaction instruments became available in Sweden, and impaction grafting with the Exeter stem was then introduced on a wide scale. It has subsequently been used in 30 hospitals with varying experience of revision total hip replacement (THR).

In 2003, we drew up plans for a national survey of the results of this operation in Sweden, between 1989 and 2002. The aim was twofold: first, to document the long-term results and complications of this procedure and secondly to study the effect of an aggregate of learning experience on the outcome.

\section{Patients and Methods}

Meetings with Swedish users of the Exeter system were held in 2002. A proforma was developed on which to document the necessary details, and this was circulated in early 2003. Each department agreed to identify 
Table I. Age and gender distribution of the 1305 hips

\begin{tabular}{lccr}
\hline $\begin{array}{l}\text { Age in years at revision in } \\
\text { five-year intervals }\end{array}$ & Female & Male & Total \\
\hline 25 to 29 & 1 & 0 & 1 \\
30 to 34 & 1 & 0 & 1 \\
35 to 39 & 1 & 1 & 2 \\
40 to 44 & 11 & 5 & 16 \\
45 to 49 & 3 & 12 & 15 \\
50 to 54 & 26 & 18 & 44 \\
55 to 59 & 41 & 28 & 69 \\
60 to 64 & 72 & 62 & 134 \\
65 to 69 & 120 & 95 & 215 \\
70 to 74 & 175 & 147 & 322 \\
75 to 79 & 171 & 113 & 284 \\
80 to 84 & 77 & 80 & 157 \\
$85+$ & 24 & 21 & 45 \\
Total & 723 & 582 & 1305 \\
\hline
\end{tabular}

Table II. The 1305 analysed hips according to the year of revision

\begin{tabular}{lccr}
\hline Year of revision & Female & Male & Total \\
\hline 1989 & 0 & 3 & 3 \\
1990 & 5 & 2 & 7 \\
1991 & 5 & 4 & 9 \\
1992 & 7 & 6 & 13 \\
1993 & 28 & 29 & 57 \\
1994 & 49 & 59 & 108 \\
1995 & 55 & 46 & 101 \\
1996 & 77 & 51 & 128 \\
1997 & 67 & 57 & 124 \\
1998 & 65 & 55 & 120 \\
1999 & 83 & 50 & 133 \\
2000 & 90 & 70 & 160 \\
2001 & 97 & 75 & 172 \\
2002 & 95 & 75 & 170 \\
Total & 723 & 582 & 1305 \\
\hline
\end{tabular}

retrospectively all femoral impaction grafting operations performed with the Exeter stem up to December 31, 2002.

We updated the material in 2007 by consulting the National Population Register to identify patients who had died between 2002 and 2007. We also asked the Swedish National Hip Arthroplasty Registry ${ }^{13}$ to identify further revisions reported to the Register during the same period. In so doing we have amended the observations censored in 2002 , adding almost five years to the observation time.

A total of 30 orthopaedic departments identified at least one femoral impaction bone grafting revision. This yielded a total of 1352 revisions. However, in two cases the patients' identification was missing and they could not be matched against the Swedish Hip Arthroplasty Registry. In another 45 cases, patient identification information, operation dates or operated sides were conflicting. A number of case notes could not be retrieved. Such loss of documentation reduced the number of analysed hips to 1305 of which 1071 were unilateral procedures and 117 bilateral. The 1188 patients ( 650 women and 538 men) had a mean age of 71 years (29 to 94 ) (Table I).
Table III. Causes of further revision

\begin{tabular}{lc}
\hline Aseptic loosening & 11 \\
Subsidence & 13 \\
Infection & 16 \\
& \\
Fracture & 17 \\
$\quad$ Femoral & 3 \\
$\quad$ Pseudarthrosis & 3 \\
$\quad$ Dislocation & \\
& \\
Hip dislocation & 1 \\
$\quad$ Stem fracture & 2 \\
Stem penetration & 1 \\
$\quad$ Unknown & 3 \\
\hline
\end{tabular}

The patients were operated on between 1989 and 2002 (Table II). Our observation time thus spanned five to 18 years. The mean time in situ of the individual stems was 97.3 months (0.1 to 210.9).

The indication for the primary THR was osteoarthritis $(\mathrm{OA})$ in 874 hips $(67 \%)$, fracture of the hip in $96(7.3 \%)$, inflammatory disease in $94(7.2 \%)$, other reasons in $87(6.7 \%)$ and unknown in $154(11.8 \%)$. The indication for revision was aseptic loosening in 1157 hips $(88.7 \%)$, infection in $89(6.8 \%)$ and various other reasons in $55(4.2 \%)$. In four cases, the reason for revision was not documented.

The impaction bone grafting revision was the first in 1044 hips (80\%), the second in $184(14.1 \%)$, the third in 21 $(1.6 \%)$ and the fourth in two $(0.2 \%)$. In 54 hips this information was unavailable. Standard-length Exeter stems were used in 1081 hips (82.8\%) and long stems (205 $\mathrm{mm}$ or longer) in $145(11.1 \%)$. In 79 stems the length was unknown.

When impaction bone grafting was introduced, the bone graft was milled into comparatively small chips ( $2 \mathrm{~mm}$ to $4 \mathrm{~mm}$ ) and squeezed by hand to remove excessive fat. Gradually, many departments began using bone mills which produced larger chips, and also began to rinse the graft in warm saline before impaction to displace the fat. We have no record of when or if at all this change was implemented in the departments in our study.

The cement almost exclusively used in revision surgery in Sweden during the period of study was Palacos with gentamicin (Heraeus Ltd, Wehrheim, Germany), possibly with the addition of vancomycin in some cases. The cement was chilled, vacuum-mixed, injected in a retrograde manner and then pressurised with a proximal seal.

Statistical analysis. The data were entered into an SPSS version II database (SPSS Inc., Chicago, Illinois) and analysed by the Cox's regression and the Kaplan-Meier survival methods with log-rank testing. All statistical calculations were performed using STATA version 10.0 for Unix (StataCorp, College Station, Texas). Statistical significance was set at a p-value $\leq 0.05$. All confidence intervals $(\mathrm{CI})$ were set at the $95 \%$ level. 
Table IV. Causes of failure and year of re-revision

\begin{tabular}{lcccccc}
\hline Year of re-revision & Aseptic loosening & Subsidence & Infection & Femoral fracture & Other & Total \\
\hline 1990 & 0 & 1 & 0 & 0 & 0 & 1 \\
1991 & 0 & 0 & 0 & 0 & 0 & 0 \\
1992 & 1 & 1 & 1 & 0 & 0 & 3 \\
1993 & 1 & 1 & 2 & 1 & 1 & 6 \\
1994 & 3 & 2 & 3 & 0 & 1 & 9 \\
1995 & 0 & 0 & 1 & 3 & 4 & 8 \\
1996 & 3 & 2 & 3 & 2 & 13 \\
1997 & 1 & 0 & 1 & 0 & 4 \\
1998 & 1 & 2 & 3 & 2 & 7 \\
1999 & 0 & 0 & 3 & 2 & 0 & 6 \\
2000 & 1 & 1 & 0 & 0 & 5 \\
2001 & 0 & 2 & 1 & 3 & 1 & 5 \\
2002 & 0 & 0 & 0 & 17 & 3 \\
Total & 11 & 0 & 16 & & 13 & 70 \\
\hline
\end{tabular}

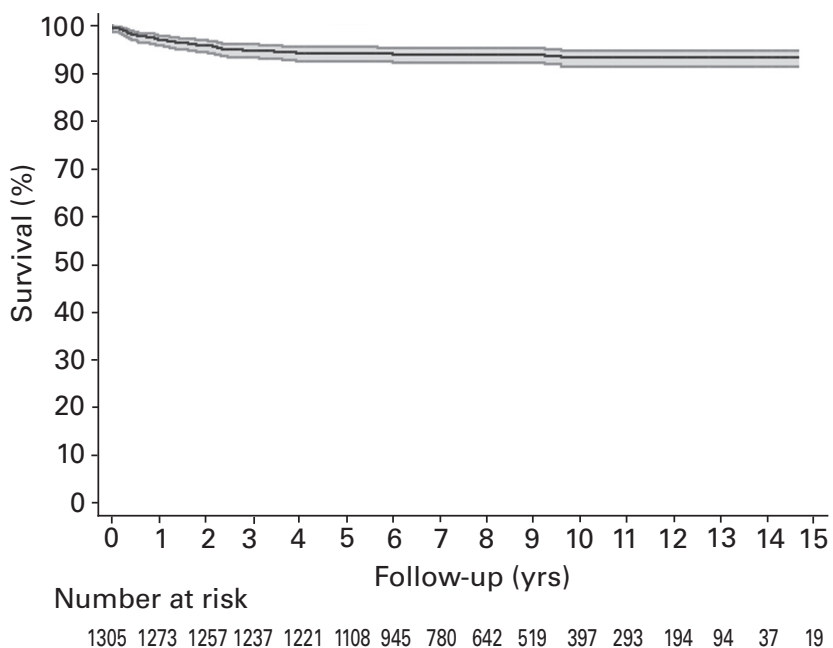

Fig. 1

Kaplan-Meier survivorship curve showing the total survival at 15 years for all causes of failure with $95 \%$ confidence intervals. Most failures occurred within the first four years.

\section{Results}

Of the 1188 patients, 143 ( 84 women and 59 men) died without further revision and 70 (41 women and 29 men) had a further revision for indications listed in Tables III and IV. Of the 70 further revisions, 57 could also be identified on the Swedish National Arthroplasty Registry. The most common causes of failure were infection and fracture of the femur, together comprising 33 cases $(47 \%)$. Aseptic loosening was seen in $11(15.7 \%)$, and subsidence sufficient enough to require further surgery in $13(18.6 \%)$. The nature of the complications varied between hospitals. However, because of the small number of failures in general, and the rarity of failure in any one hospital in particular, we have not found it meaningful to compare individual departments.

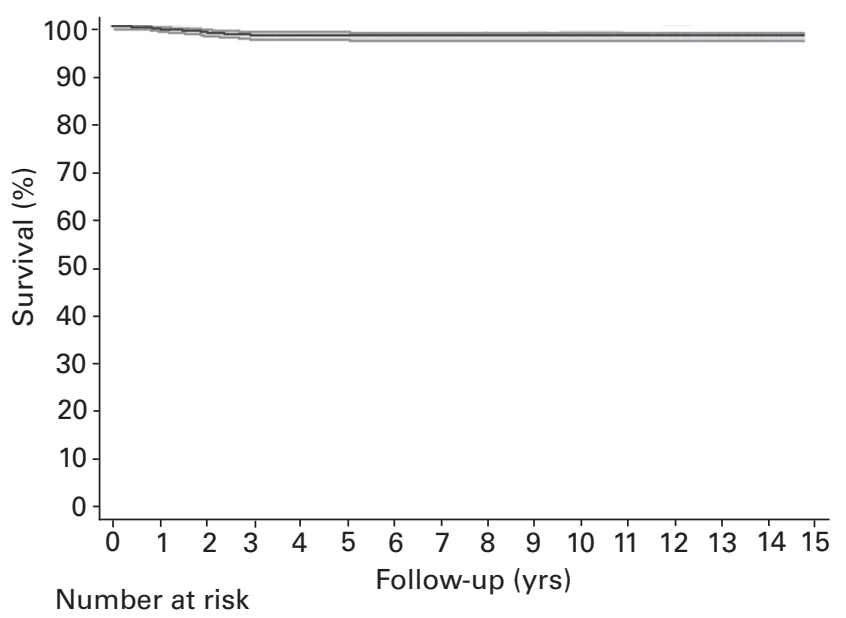

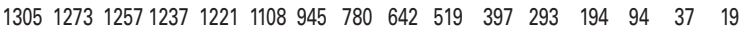

Fig. 2

Kaplan-Meier survival curve showing the survival at 15 years of impaction bone grafting Exeter stems with re-revision for aseptic loosening and subsidence combined.

Survival related to cause of failure. Using the Kaplan-Meier survivorship analysis for all causes of failure, the survivorship at 15 years was $94.0 \%$ (95\% CI 92 to 96) for women and $94.7 \%$ (95\% CI 92 to 96 ) for men (Fig. 1). The survivorship at 15 years with aseptic loosening as the endpoint was $99.1 \%$ (95\% CI 98.4 to 99.5 ), with infection $98.6 \%$ (95\% CI 97.6 to 99.2 ), with subsidence $99.0 \%$ (95\% CI 98.2 to 99.4 ) and with fracture $98.7 \%$ (95\% CI 97.9 to 99.2) (Fig. 2). In all 65 of 70 recorded complications occurred within 48 months. Later complications included one case of aseptic loosening, two of infection, one of stem fracture and one unclassified.

Survival related to primary diagnosis. With the primary diagnosis of OA, the survivorship at 15 years was $95 \%$ (95\% CI 93 to 96). The survivorship of hips with inflammatory disease was the same as that of OA up to nine years but 
then one case failed, reducing the survivorship at 15 years to $90 \%$ (95\% CI 79 to 95$)$. The number of patients in this group was small, with 94 at the outset and 40 at the final census. Patients with previous hip fracture did almost as well as the OA group (93\% at 15 years (95\% CI 85 to 96$)$ ).

Survival related to previous mode of failure. Grafting was undertaken because of previous aseptic loosening in 1210 hips. The survival of these was $95 \%$ (95\% CI 93 to 96) at 15 years. Hips on which grafting had been done after an infection had a survival of $94 \%(95 \%$ CI 87 to 98$)$ at 13 years. However, there were 56 hips in which the cause of failure was classified as 'other', and these had a combined survivorship of $82 \%$ ( $95 \%$ CI 69 to 90 ).

Surgical experience. This was shown to be a significant factor for a successful outcome (Cox-regression trend-test, $\mathrm{p}=0.021$ ). Departments which had carried out 100 operations or more were found to be statistically significantly better as a group compared with the others $(\log$-rank test, $\mathrm{p}=0.03)$. For all causes of failure, the survivorship at ten years was $96.1 \%$ (95\% CI 93.5 to 97.5 ) and $93.5 \%$ (95\% CI 91.4 to 95.0 ), respectively.

Calculating the relative risk (RR) of further revision per calendar year proved to be problematic because of the small number of failures (Tables III and IV). Instead, we calculated the survivorship for all causes of failure of hips revised before and after January 1, 1998. The reason for choosing this date was twofold. In 1998 the new instrumentation was introduced and this date also provided a reasonably even-sized division of the material. The survival at nine years of the hips revised after January 1,1998 was $96.5 \%$ (95\% CI 94 to 98$)$ and that of the hips revised before 1998 was $91.1 \%$ (95\% CI 87 to 94 ).

Other analyses. No statistically significant differences in survival could be found with respect to the technique of impaction or stem length ( $\mathrm{RR}=1.7,95 \%$ CI 0.7 to 4.2$)$, for impaction without versus with instruments $(\mathrm{p}>0.427)$, and for long versus standard-length stems $(\mathrm{RR}=0.7,95 \%$ CI 0.3 to 1.7). Age at revision and gender also had no statistically significant influence on the risk of further revision (age at revision $\mathrm{RR}=1.01 ; 95 \%$ CI 0.95 to 1.07 per year and gender $\mathrm{RR}=1.4 ; 95 \% \mathrm{CI} 0.5$ to 3.7). Comparing the survivorship of two sub-groups, age $<50$ versus age $>50$ years and age $<60$ versus age $>60$ years for both men and women, no statistically significant difference was seen, although numbers were sometimes small $(\mathrm{p}=0.403$ and $\mathrm{p}=0.422$, respectively).

Entering gender, age, stem length, year of revision (before/after 1998) and the number of earlier revisions as factors in a Cox regression analysis, we found that only the year of revision and the number of previous revisions were statistically significant predictors of failure $(\mathrm{p}<0.001)$, whereas the number of previous revisions was slightly above the level of significance $(p=0.056)$.

\section{Discussion}

Our study is the first to provide a comprehensive overview of the outcome of femoral impaction bone grafting in general. The results are biased towards poorer outcomes on clinical practice, since the accumulated learning experience of
30 orthopaedic departments in Sweden, is included. They provide a baseline for discussions on the relative merits of impaction bone grafting for femoral revision. Impaction bone grafting can be seen as an example of the step-wise introduction of new technology as suggested by Malchau. ${ }^{14}$ It was first tried in vitro and then in vivo in the originating centres before being introduced on a national scale with supplementary radiostereogrammetric analysis (RSA) in a few centres and finally evaluated in the present register study.

Despite our efforts to ensure the completeness of the data it is of note that only 57 of the 70 further revisions $(81.4 \%)$ were detected through the Swedish National Hip Arthroplasty Registry. ${ }^{13}$ The discrepancy is of concern and its causes are unknown, but our material is a form of external audit of the National Registry and highlights the value of future similar endeavours.

The projected survivorship at 15 years of $94 \%$ (95\% CI 92 to 96) for all causes of failure must by all standards be regarded as good.

Aseptic loosening when it occurred was shown to be an early phenomenon, almost always appearing within four years post-operatively. From earlier studies it seems, both radiologically ${ }^{6}$ and histologically ${ }^{15}$ that very little change takes place after that time. However, Linder ${ }^{15}$ showed in a retrieval study that the impacted allograft was not always replaced by living bone and the various supporting tissues were apparently mechanically sufficient. ${ }^{16}$ It is not clear where the division lies between aseptic loosening and subsidence. In an RSA study ${ }^{17}$ of 15 impaction-grafted Exeter stems it was shown that three were stable at between two and five years post-operatively, 11 showed minimal migration and one was asymptomatic but migrating continuously, and therefore by definition loose, even though it had not been revised. It might therefore be appropriate to consider aseptic loosening and subsidence requiring further revision as a single entity of aseptic failure. Our failure rate was no more than about $2 \%$ at 15 years.

Although experience with the technique of impaction bone grafting is one factor behind the reduction of complications, the difference between experienced and inexperienced departments respectively undertaking more than or fewer than 100 impaction bone grafting revisions, was less than $3 \%(96.1 \%$ vs $93.5 \%)$ at ten years.

Seen in this perspective, our results are not dramatically different from those of the originating centres. ${ }^{1,6,7}$ Contrary to the opinion that impaction bone grafting requires considerable time to learn, ${ }^{2}$ our data suggest that the technique is standardised and can be learned quickly. The most common aseptic complication was fracture, similar to that of most studies. ${ }^{4,10,11}$ The reason for this probably lies in the difficulty of adequately preparing the highly variable femur for the impaction, highlighting the need for careful preoperative planning.

At the inception of impaction bone grafting oversized trial components were used as impactors. Subsequently, dedicated instruments were produced with the intention of 
using only standard-length stems, with the aim of reestablishing the anatomy of a primary THR. However, this might have contributed to several fractures about the tip of the impacted stem since this is a common site of endosteal lysis. In principle, cortical defects of Endoklinik grades 3 and $4^{18}$ heal well even when short stems are used, ${ }^{1}$ provided that proper post-operative precautions are taken. ${ }^{19}$ Although a number of insufficiency fractures undoubtedly did occur at the tip of the short stem, we agree with Schreurs et $\mathrm{al}^{7}$ that such fractures should not be seen as a failure of impaction grafting as such, but rather as a failure of our means of assessing cortical bone regeneration.

It was not until 1998 that a comprehensive array of implants, impactors and meshes were available, and this has coincided with a reduction of early failures. However, we were unable to find a difference in survivorship for short and long stems, indicating that there might be additional reasons for this apparent cause-and-effect relationship. This reduction in failures may also have been due to a gradual change in patient selection, such as a preference for distally-fixed uncemented prostheses in some revision situations.

We recognise the weakness of our study. Like all other complications based on a register in which there has been no analysis of clinical scores or radiography, potential failures or ominous radiological appearances may have been missed. Additionally, the severity of bone loss is unknown which might have influenced the outcome. The prevailing revision method at the time of the introduction of impaction bone grafting was the re-cementing of a longer stem into the femur. From register studies it was known that this gave a $75 \%$ survival at eight years in active patients, ${ }^{20}$ but was perceived to be better in the elderly, as subsequently confirmed by Hultmark et al. ${ }^{21}$ It is therefore likely that recementing and impaction bone grafting were used in parallel during the course of our study, impaction bone grafting being reserved for the more advanced cases. When impaction bone grafting was introduced it was advised for revision when it was unlikely that bone cement could achieve successful interdigitation. ${ }^{1}$

Initially, impaction bone grafting was met with much scepticism in Sweden with concerns over viral transmission, graft resorption and re-infection from dead allograft placed in a previously infected bone bed. Such concerns led a number of departments opting for uncemented distally-fixed stems. It seems now that both methods are accepted, and that comparison of their benefits is possible.

Today, distally-fixed, uncemented stems are increasingly used for expediency in addressing extensive proximal femoral pathology. There is no doubt that this is a very rewarding technique, combining good fixation and proximal bone regeneration, but nevertheless requiring experience to perfect. ${ }^{22}$ Longer term analyses of distally secured uncemented stems indicate a survival rate from all causes of failure between $86 \%$ and $95 \%$ at ten to 15 years. ${ }^{23-25}$

Overall, the results of our survey suggest that the survival of femoral impaction bone grafting revision THR using the
Exeter stem is on a par not only with uncemented revision methods, but even with primary THR. Most of the early misgivings about the method have been allayed since there have been no reports of an accelerating incidence of late failures, endosteal lysis or infection. We conclude that there is no reason for surgeons who are comfortable (with the method) and experienced in its use to abandon impaction bone grafting.

The clinical work in the following hospitals formed the basis for our study, and their help in compiling our database is appreciated. We thank the orthopaedic surgeons and the Departments of the Hospitals, H. Franzén in Ängelholm, L. Lundmark in Boden, P. E. Persson in Kristianstad, B. Lund-Petersen in Falun, G.Ullmark in Gävle, N. Ramberg in Helsingborg, P. Ljung in Hässleholm, S. Wijkström in Eksjö, H. Hedlund in Huddinge, B. Brodd in Kalmar, M. Henriksson in Karlstad, C. Olsson in Karlskrona, L. Weidenhielm in Solna, S. Hallnerg in Lindesberg, G. Flivik in Lund, L. Sanzén in Malmö, B. Horn in Motala, S. Olsson in Norrköping, B. Granath in Örebro, P. Ramberg in Östersund, S. Eriksson in Piteå, B. Skytting in SÖS Stockholm, H.-C. Hyldahl in St Göran Stockholm, A. Rünow in Trelleborg, C. Strömberg in Uddevalla, U. Lind in Västerås, J. Alkstedt in Västervik, M. Fagerlund in Växjö, R. Landin in Ystad and K. Persson in Norrälje.

No benefits in any form have been received or will be received from a commercial party related directly or indirectly to the subject of this article.

\section{References}

1. Gie GA, Linder $\mathbf{L}$, Ling RS, et al. Impacted cancellous allografts and cement for revision total hip arthroplasty. J Bone Joint Surg [Br] 1993;75-B:14-21.

2. Morgan HD, McCallister W, Cho MS, Casnellie MT, Leopold SS. Impaction allografting for femoral component revision. Clin Orthop 2004;420:160-8.

3. Board TN, Rooney P, Kearney JN, Kay PR. Impaction allografting in revision total hip replacement. J Bone Joint Surg [Br] 2006;88-B:852-7.

4. Ornstein E, Atroshi I, Franzén H, et al. Early complications after one hundred and forty-four consecutive hip revisions with impacted morselized allograft bone and cement. J Bone Joint Surg [Am] 2002;84-A:1323-8.

5. Atroshi I, Ornstein E, Franzén H, et al. Quality of life after hip revision with impaction bone grafting on a par with that 4 years after primary cemented arthroplasty. Acta Orthop Scand 2004;75:677-83.

6. Halliday BR, English HW, Timperley AJ, Gie GA, Ling RSM. Femoral impaction grafting with cement in revision total hip replacement: evolution of the technique and results. J Bone Joint Surg [Br] 2003;85-B:809-17.

7. Schreurs BW, Arts JJ, Verdonschot N, et al. Femoral component revision with use of impaction bone-grafting and a cemented polished stem. J Bone Joint Surg [Am] 2005:87-A:2499-507.

8. Edwards SA, Pandit HG, Grover ML, Clarke HJ. Impaction bone grafting in revision hip surgery. J Arthroplasty 2003;18:852-9.

9. Mahoney CR, Fehringer EV, Kopjar B, Garvin KL. Femoral revision with impaction grafting and a collarless, polished, tapered stem. Clin Orthop 2005;432:181-7.

10. Fetzer GB, Callaghan JJ, Templeton JE, et al. Impaction allografting with cement for extensive femoral bone loss in revision hip surgery: a 4- to 8-year follow-up study. J Arthroplasty 2001;16:195-202.

11. Cabanela ME, Trousdale RT, Berry DJ. Impacted cancellous graft plus cement in hip revision. Clin Orthop 2003;417:177-82

12. Yim SJ, Kim MY, Suh YS. Impaction allograft with cement for the revision of the femoral component: a minimum 39-month follow-up study with the use of the Exeter stem in Asian hips. Int Orthop 2007;31:297-302.

13. No authors listed. The Swedish National Hip Arthroplasty Registry. http:// jru.orthop.gu.se (date last accessed 5 March 2009).

14. Malchau H. On the importance of stepwise introduction of new hip implant technology. Thesis. Goteborg: Goteborg University, 1995.

15. Linder L. Cancellous impaction grafting in the femur: histological and radiographic observations in 6 autopsy femurs and 8 biopsies. Acta Orthop Scand 2000;71:543-52.

16. Tägil M, Aspenberg P. Fibrous tissue armoring increases the mechanical strength of an impacted bone graft. Acta Orthop Scand 2001;72:78-82.

17. Ornstein E, Franzén $\mathbf{H}$, Johnsson $\mathbf{R}$, et al. Hip revision using the Exeter stem, impacted morselized allograft bone and cement: a consecutive 5-year radiostereometric and radiographic study in 15 hips. Acta Orthop Scand 2004;75:533-43.

18. Engelbrecht DJ, Weber FA, Sweet MB, Jakim I. Long-term results of revision total hip arthroplasty. J Bone Joint Surg [Br] 1990;72-B:41-5

19. van Biezen FC, ten Have BL, Verhaar JA. Impaction bone-grafting of severely defective femora in revision total hip surgery: 21 hips followed for 21-85 months. Acta Orthop Scand 2000;71:135-42 
20. Strömberg CN, Herberts P, Palmertz B. Cemented revision hip arthroplasty: a multicenter 5-9-year study of 204 first revisions for loosening. Acta Orthop Scand 1992;63:111-19.

21. Hultmark $\mathbf{P}$, Kärrholm J, Strömberg $\mathbf{C}$, et al. Cemented first-time revisions of the femoral component: prospective 7 to 13 years' follow-up using second-generation and third-generation technique. J Arthroplasty 2000;15:551-61.

22. Gutiérrez Del Alamo J, Garcia-Cimbrelo E, Castellanos V, Gil-Garay E. Radiographic bone regeneration and clinical outcome with the Wager SL revision stem: a 5-ear to 12-year follow-up study. J Arthroplasty 2007;22:515-24.
23. Engh CA Jr, Ellis TJ, Koralewicz LM, McAuley JP, Engh CA Sr. Extensively porous-coated femoral revision for severe femoral bone loss: minimum 10-year follow-up. J Arthroplasty 2002;17:955-60.

24. Böhm P, Bischel 0. The use of tapered stems for femoral revision surgery. Clin Orthop 2004;420:148-59.

25. Ochs BG, Volkmann R, Eingartner C, et al. Treatment of large femoral bone defects: 15 year experience with the cementless Bicontact revision stem with distal interlocking. Z Orthop Unfall 2007;145 (Suppl 1):34-9. 